\title{
SPECIES DIVERSITY OF PLIOCENE-RECENT MOLLUSK FAUNAS OF THE WESTERN ATLANTIC: IMPLICATIONS FOR CLIMATIC HISTORY
}

ALLMON*, Warren D., Dept. of Geology, University of South Florida, Tampa, FL 33620, U.S.A.; PORTELL, Roger, Florida Museum of Natural History, University of Florida, Gainesville, FL 32611, U.S.A.; ROSENBERG, Gary, Academy of Natural Sciences of Philadelphia, 1900 Benjamin Franklin Parkway, Philadelphia, PA 19103, U.S.A.; SCHINDLER, Kevin, Florida Museum of Natural History, University of Florida, Gainesville, FL 32611, U.S.A.

The late Cenozoic history of mollusks in the tropical and subtropical Western Atlantic has traditionally been viewed as one of decreasing species richness via a series of more or less discrete extinction episodes, from a Mio-Pliocene peak to the depauperate (relative to the Eastern Pacific) fauna of today. These extinction episodes have been interpreted by some authors as responses to climatic deterioration, especially climatic cooling associated with northern hemisphere glaciation.

Two new species-level compilations of gastropods suggest, however, that this traditional scenario may be oversimplified.

1) A new (but still preliminary) compilation of species from the Late Pliocene "Pinecrest Sand" of southern Florida contains 365 species. This compilation is based mainly on specimens > $5 \mathrm{~mm}$ in size taken from bulk samples collected in quarries near Sarasota and held in the collections of the Florida Museum of Natural History; when smaller specimens are considered, and systematic analysis of larger forms from this and other localities is complete, it is likely that this number will increase significantly. The Pinecrest has been systematically neglected; although our count is preliminary, it represents the most complete and well-documented compilation available for this spectacular and highly diverse fauna.

This number for the Pinecrest compares with 479 species of gastropods in the overlying Late Pliocene-Early Pleistocene Caloosahatchee "Formation" (data of Campbell et al., 1975). 178 gastropod species are in common between the two units, yielding an extinction level of $51.2 \% .301$ (62.8\%) of the Caloosahatchee gastropod species are not present in the Pinecrest.

Stanley (1986) listed 211 species of bivalves in the Pinecrest and 150 in the Calooshatchee, with 110 in common, giving an extinction level of $47.9 \% .40(26.7 \%)$ of the Caloosahatchee bivalve species are not present in the Pinecrest.

2) A new compilation of all described Recent shelled gastropods in the Western Atlantic (Cape Hatteras to Rio de Janeiro) contains 2800 species (2418 of which were described before 1972), compared to the 2360 species listed by Keen (1971) for the Recent Eastern Pacific. These two lists compare similar size and depth ranges, and indicate that the Western Atlantic gastropod fauna is not less species-rich than the Eastern Pacific gastropod fauna.

In addition, a growing body of evidence from other studies (ostracodes, foraminifera, isotopic analyses) indicates that the Late Pliocene was not a time of marked climatic cooling, at least not in the Western Atlantic. Still other studies (e.g., of the biogeography of turritelline gastropods, isotopic analyses on both sides of the Central American Isthmus, paleoceanographic modelling) suggest that the most significant environmental changes at this time may have been associated with changes in nutrient levels.

Taken together, these very preliminary results suggest a more complex history for the Western Atlantic mollusk fauna than previously envisioned. If the Plio-Pleistocene was a time of significant turnover but not significant diversity decline, and gastropods of the Recent Western Atlantic are not less diverse than their Eastern Pacific counterparts, then the patterns to be explained must be reexamined. Late Cenozoic extinction may have been significant in the Western Atlantic, but it may have been accompanied by high levels of diversification.

In any case, those faunal changes that did occur at this time may have been caused as much or more by changes in nutrient levels as in temperature. 